\title{
AUTHOR INDEX Volume 7
}

H. Ahmad see Suraya, H.

S. Ahmed see Suri Babu, G.

S. Al Hawari see Alryalat, $\mathrm{H}$.

H. Alryalat \& S. Al Hawari Towards Customer Knowledge Relationship Management: Integrating Knowledge Management and Customer Relationship Management Process

P. Ardimento, D. Caivano, M. Cimitile \& G. Visaggio Empirical Investigation of the Efficacy and Efficiency of Tools for Transferring Software Engineering Knowledge

G. Athiappan see Balamurugan, S. A. A.

S. A. A. Balamurugan, G. Athiappan, M. M. Pandian \& R. Rajaram Classification Methods in the Detection of New Suspicious Emails

D. Caivano see Ardimento, P.

E. Y. Cheng \& Y. L. Liu Adoption of Knowledge Management Technologies and Organisational Culture: An Exploratory Study

M. Cimitile see Ardimento, P.

J. W. Coffey \& T. Eskridge Case Studies of Knowledge Modeling for Knowledge Preservation and Sharing in the US Nuclear Power Industry

W. Dai \& L. Uden Empowering SME Users Through Technology Innovation: A Services Computing Approach

K. Duraiswamy \& N. Maheswari Sensitive Items in Privacy Preserving - Association Rule Mining

J.-P. B. Ekionea see Swain, D. E.

T. Eskridge see Coffey, J. W.

K. S. Gupta see Suri Babu, G.

R. K. Gupta see Pillai, S.

R. Gutierrez see Reforgiato, D.
3 (2008) 159

2 (2008) 83

3 (2008) 145

3 (2008) 145

3 (2008) 197

3 (2008) 209

3 (2008) 209

3 (2008) 197

1 (2008) 15

3 (2008) 197

3 (2008) 173

4 (2008) 267

1 (2008) 31

2 (2008) 113

3 (2008) 173

2 (2008) 83

3 (2008) 135

4 (2008) 231
S. Hariharan \& R. Srinivasan

A Comparison of Similarity Measures

for Text Documents

1 (2008) 1

K. S. Hong see Ngui, K. S.

4 (2008) 219

P. Hurmelinna-Laukkanen see

Jantunen, A.

3 (2008) 187

A. Jantunen, K. Puumalainen \& P.

Hurmelinna-Laukkanen Knowledge

Sharing and Innovation Performance

3 (2008) 187

R. Kant \& M. D. Singh Knowledge

Management Implementation:

Modeling the Barriers

4 (2008) 291

M. Koenig \& K. Neveroski The Origins and Development of Knowledge

Management

P. Kumarawadu Achieving Competitive Advantage through Knowledge Management Initiatives in Small and Medium Software Industry

4 (2008) 255

J. Li, L. L. Zhang \& Y. Shi Research on Evaluation Model of Organisational Knowledge Assets

1 (2008) 47

1 (2008) 15

1 (2008) 31

N. Maheswari see Duraiswamy, K.

T. G. Merino see Santos-Álvarez, V.

M. Mittal Personal Knowledge

2 (2008) 123

Management: A Study of Knowledge

Behaviour of Academicians

2 (2008) 93

2 (2008) 83

F. Nazem The Compilation of Math

Pattern for Productivity in

Educational Organisations, Service

Organisations (Municipalities), and

Industrial Organisations Based on

Organisational Climate in Iran

2 (2008) 75

K. Neveroski see Koenig, M.

K. S. Ngui, P. Songan \& K. S. Hong

Organisational Learning Capability of

Malaysia SMEs: Examining the

Effects of Entrepreneurial Orientation and Human-Capital Development

Practices
4 (2008) 243

$4(2008) 219$ 
M. M. Pandian see Balamurugan, S. A. A.

B. E. Perrott Towards a Model of

Transformation: Manager's

Perceptions of Transformation in an E-Business Environment

S. Pillai, R. K. Gupta \& K. B. C.

Saxena From Rhetoric to Reality: An Enquiry into KM Initiatives in an Organisation of Higher Learning

S. Piramuthu Adaptive Framework for

Collisions in RFID Tag Identification

K. Puumalainen see Jantunen, A.

R. Rajaram see Balamurugan, S. A. A.

J. Ranjan Knowledge Management in Business Schools

D. Reforgiato, R. Gutierrez \& D.

Shasha GraphClust: A Method for

Clustering Database of Graphs

M. Roknuzzaman \& K. Umemoto Knowledge Management's Relevance to Library and Information Science: An Interdisciplinary Approach

M. Salisbury A Framework for Reusing and Repurposing Knowledge Work in Organisations

V. Santos-Álvarez \& T. G. Merino The Export Decision and the Cognitive Limitation of the Managers
K. B. C. Saxena see Pillai, S.

3 (2008) 209

3 (2008) 135

1 (2008) 9

3 (2008) 187

3 (2008) 209

1 (2008) 55

4 (2008) 231

4 (2008) 279

2 (2008) 101

2 (2008) 123

Measurement Approach Strategy with Petri Nets
3 (2008) 135

4 (2008) 231

1 (2008) 47

4 (2008) 291

4 (2008) 219

1 (2008) 1

3 (2008) 159

2 (2008) 83

D. E. Swain \& J.-P. B. Ekionea A Framework for Developing and Aligning a Knowledge Management

2 (2008) 113

M. Tavana Knowledge-Based Expert System Development and Validation

1 (2008) 37

4 (2008) 267

4 (2008) 279

3 (2008) 197

1 (2008) 47 